\title{
Language and Stupidity
}

\section{Opinion}

Volume 2 Issue 1- 2021

\author{
Author Details \\ James F Welles* \\ East Marion, USA \\ *Corresponding author \\ James F Welles, P O Box 17, East Marion, New York, USA \\ Article History
}

Received: January 22, 2021 Accepted: January 30, 2021 Published: February 05, 2021

\begin{abstract}
Language evolved as a means of sharing information and promoting group cooperation, but as a side effect, it shaped the human psyche by the very nature of words. These are really audible symbols which represent selected, generalized aspects of the environment. In this sense, language is a code [1], with each particular language necessarily biased and restrictive as it defines perceptions [2] in terms of the specific culturally determined categories to which the encoded symbols are attached.
\end{abstract}

\section{Opinion}

It is the linguistic requisite for categorizing which makes the human way of experiencing nature different from that of all other species. While making the human psyche unique, our verbal tradition prohibits "Freedom of experience" from the human condition, as only feral children can escape the subjective impact that the specific verbal values of his given reference group imposes [3]. Each language segments the environmental continua (motion, color, sound, etc.) into various arbitrary categories. Collectively, these provide the cognitive context in which members of the language group think, feel and evaluate experience: that is, we live by symbols [4].

Although categorizing permits the streamlining of some perceptions for the sake of mental efficiency, there are drawbacks. For example, every group is somewhat compromised by the very human tendency to indulge in "Stereotyping" [5]. This is a process of "Over generalizing" to the point that important discriminable experiences are treated equally [6]. As we go through life, we fill out our verbal categories with discrete items or events. When we deal with people, for example, certain salient characteristics which members of some perceived group share in common (skin color, language, religion, etc.) are considered determining factors in evaluating the group in general. For the sake of expedience, individual variation may then be ignored and generalizing carried to the extreme that all people who can possibly be placed in a given pigeon-hole are lumped together mentally under the label for that category.

Not only do we lose information to stereotyping, but the many groups of people become separated from each other because their different languages segment the common environment into different categories. Sad to say, when people in "Opposing" cultures experience the same stimuli differently, they often squabble about their perceptions and reactions rather than enlightening each other with complementary views of the world. Only in superficial matters can alternative interpretations be accepted as interesting or humorous without being threatening. On the other hand, most of history's great religious and military conflicts had their origins in perceptual/philosophical differences of competing groups which found they could not live in both the same and different worlds ${ }^{\mathrm{a}}$.

Such conflicts underscore the point that language functions as a "Defining system" for people [7]. It is through words that "Relevance" is determined for each of us by our culture with behavior being shaped by the structuring of our reactions to what we construe to be relevant. What may really be relevant to one's best interest may not be identified as such by a necessarily if unfortunately biased language system.

This bias of the language system is based on the descriptive categories and labels used to construct a person's cognitive world. As the schema is formed, accuracy and objectivity of perceptions are sacrificed for and by euphemisms. These enhance self-esteem by giving favorable interpretations of the actions of the individual and his reference group and negative stereotypes to rivals and opponents. This verbal phenomenon can be carried beyond the selection of words even to their pro-nunciation as happened, for example, with the affected Spanish accent favored among the leftist elites of the United States in the 1980's to show their support for the pro-Soviet regime in "Kneecar-AH-gew-ah" [8].

As for terminology, when dealing with Vietnam, the Johnson administration began with a humanistic way of thinking and talking about the war but ended up following the lead of the military. The ${ }^{a}$ For a humorous look at Democratic vs. Republican lingo, see Why Democrats and Republicans Literally Speak Different Languages. 
change to a detached attitude and then to a dehumanizing outlook was facilitated by euphemisms. "Gooks" were to be "Converted" into "Body counts" by "Defoliation" and "Surgical air strikes"- itself a misnomer for inaccurate bombing-which were to accomplish "Attrition" which would precede "Pacification" [9]. It was as difficult to argue against such strategy as it was easy to misjudge American's best interest in those terms, as opposed to "Napalm" and "My Lai" [10].

A few years later, the Nixon administration had a similar problem judging its own best interest and literally got hung up on the terms "Executive privilege" and "National security". The Nixonians were also disposed to use derogatory terms for their presumed enemiesmeaning the press, students, hippies, Jews, Italians, Germans, blacks and liberals in the State Department and Congress [11] and committed to destroying anyone $\mathrm{e}^{\mathrm{b}}$ who did not support the Nixon team [12].

Along with defining means and experience, words shape the schema by directing attention [6] to certain facets of the environment which are deemed important by the verbal value system. Each language system has an inherent tendency to emphasize certain experiences while others are trivialized. Thus, accuracy of overall perception and objectivity of interpretation are sacrificed to verbal appeal as people focus on particular stimuli at the expense of others [13]. Of course, events of expected significance receive the most attention and analysis-particularly if they pose either a serious threat to the schema or an opportunity for a triumphant achievement worthy of the Superego Seal of Approval.

Language further serves as a memory system [14], in that categorized, encoded experiences act as a basis for comparing the present with the past and for projecting future expectations. Naturally, the process of memory formation is systematically skewed off by forgetting some events that happened [15] and including others that did not. Thus, some aviation accidents (and even more so, near misses) can be redefined out of existence while fantasy provides a rosy picture of what self-serving experts at the FAA (Flying Accidents Administration [16]) can trick themselves into interpreting and believing. The worst that can be said about language in this regard is that it allows people to remain firmly in touch with their delusions, or, as Goethe's Mephistopheles believed: "With words, you can do anything" [17].

While examining the role language plays in the formation and functioning of the schema, we have considered it as a system for encoding, categorizing, stereotyping, defining, focusing and memorizing. We should not forget that it also functions as a communication system, making the individual's schema a product of and contributor to the group creed. As a means of sharing experiences, language is quite efficient, but as a means of permitting people to talk to and about themselves realistically, it is too biased to allow accurate self-analysis.

As a belief system, the schema promotes coping with some problems while limiting the ability to recognize even the existence of others. The schema promotes coping with acknowledged problems if the discrepancy between verbal beliefs and necessary behavior is emotionally tolerable, so in such situations, both individual and group efficiency is enhanced ${ }^{c}$. However, when the discrepancy is so pronounced as to make people self-conscious, and when coping has to be treated as heresy, psychological and social disruption result from delusive stupidity-the learned corruption of learning.

Interestingly enough, living out the expressed creed-that is, living up to the ideals-can also be aggravating to the devout who flout their

${ }^{b}$ In this vein, Nixon aid Charles Colson developed an enemies list, membership of which became a backhanded compliment extended to Steve McQueen, Gregory Peck, Barbara Streisand, Paul Newman, Jane Fonda, Andy Warhol, the presidents of Yale, the Harvard Law School, MIT and World Bank, and honored Senator Edmund Muskie, Walter Mondale and Edward Kennedy. (Wheen. 97.) But not Jim Welles.

${ }^{c}$ A rather comical case occurred during the American Revolution whentask master Barron Von Steuben, who did not speak English wanted to swear at the troops he was training. A special interpreter had to be found to accommodate him. (Fisher, D. The Patriots. Henry Holt; NY. p 178.) beliefs in daily life. Christ was crucified for fulfilling prophesies and embodying ideals. Like most great rebels, he endeavored to live up to stated standards; unlike most, he did. For example, his kicking money lenders out of the temple was an expression of his intolerance for organized impurity [18]. Such a person may be a great model for the dispossessed but is very dangerous for the establishment, so he was betrayed by the leaders of his own community. In this case, they responded in a manner typical of authorities who would be displaced if their promises were realized, and they had no difficulty recognizing what course of action was in their own immediate best interest ${ }^{\mathrm{d}}$. His crucifixion was an allegorical warning for everyone that the more one lives up to expressed ideals, the more likely he will suffer for the sin of doing so [19].

In the absence of whistle blowers, who are usually persecuted to the degree that they live up to the creed, language maximizes the potential of a social group to cooperate at whatever is accepted as necessary. Ironically, it promotes cooperation among members by inhibiting an appreciation of what it is they are doing or to what extent they may have over- or underdone it. Hence, although language normally functions as a screen between people and their environment, it can become a barrier if perception and cognition become skewed off and distorted for the sake of biased values.

In the two dimensional world of the schema, information from the reality of the behavioral environment is often redefined by the social imperative of language. An individual may find himself experiencing momentary cognitive dissonance [20] when finding incoming data from the world of "Doing" contradicting or conflicting with his ideology - the system of ideas built on his established beliefs. The usual reaction in such a situation is to "Save the schema" at the expense of learning about the environment. Thus, numerous Freudian defense mechanisms (e.g., rationalization, repression, suppression, etc.) keep individuals content with their superego value systems, albeit at the cost of improving their behavioral schemas.

Physical reality may be a better source of information, but social values are preferable [21], as they are comforting and reassuring even while they are misleading. The social world is really a symbolic environment of subjective judgments, all routinely condoned and defined by the prevailing language system. Incoming perceptions are compared to the established schema, and if a way of fitting them in can be found, it will be. If none can be found, the data are usually rejected by the defense mechanisms mentioned above. In more extreme cases, undeniable perceptions may force an uncomfortable awareness on an individual (or discussions in a group) which eventually lead to a new, more inclusive schema. This changing of one's mind is the last resort, however, particularly if it tends to isolate an individual from his social group.

Finally, language extends to matters which are beyond confirmationthat is, matters of the imagination. The universal presence of this facet of human affairs attests to its survival advantage, although there is obviously need for diplomatic caution when evaluating the reality of any such conjured phenomena or processes. Put the other way, there is no monkey dumb enough to give up a real banana now for a promise of all the bananas it can eat after it is dead. If there is some psychological advantage to human individuals who believe stories of an afterlife, there is even more gained by groups which collectively share and coordinate activities based on myths.

\section{Acknowledgement}

None.

\section{Conflicts of interest}

The author has no conflicts of interest.

dTo the consternation of devotees of "Cognitive dissonance" theory, which needs to be modified to explain why there is dissonance when creed and deed fit together. 


\section{References}

1. Smith R, Sarason I, Sarason B. Psychology: The Frontiers of Behavior. New York: 1982; pp. 215.

2. Langer E. The Power of Mindful Learning. Addison Wesley: 1997.

3. Whorf B. Science and Linguistics. In Language, Thought, and Reality: Selected Writing of Benjamin Lee Whorf. J Carroll (eds), MIT Press: Cambridge; 1959.

4. Frankfurter Jus F. Quoting O. Holmes in Minersville School District. Gobitis; 1950

5. Lippmann W. Public Opinion. Harcourt: New York; 1922.

6. Brown R, Lenneberg E. Studies in linguistic relativity. In Readings in Social Psychology. E Maccoby, et al. (eds); Holt, Rinehart and Winston: New York; 1958.

7. Sapir E. Cited in Language in Culture and Society: A Reader in Linguistics and Anthropology. D Hymes Harper (eds), New York: 1965.

8. Hayward S. The Age of Reagan: The Conservative Counterrevolution. Crown: New York; 2009: pp. 262.

9. Janis I. For a amusing presentation of terms for "Death". J Michener (eds). Random House: New York; 1994.

10. Schlesinger A. The Cycles of American History. Some of the terms in the middle of this paragraph were also from Schles. To up-date it, someone's
"Freedom Fighter" is someone else's "Terrorist". Houghton Mifflin: Boston; 1986: pp. 433.

11. Wheen F. Strange Days Indeed. Public Affairs: New York; 2009: pp. 96 118.

12. Krough E. Strange Days Indeed. Wheen F (eds) Public Affairs: New York; 2009.

13. Herskovits M. Man and His Works. Knopf: New York; 1950: pp. 542.

14. Durbin M. Cognitive anthropology. J Honigmann (eds). In: The Handbook of Social and Cultural Anthropology. Rand McNally: Chicago; 1981: pp. 450.

15. Wright J. Get Well Soon. Holt: New York; 2017.

16. Levin A. Skepticism surrounds FAA 'customer initiative'. The Situation Room. Story about the FAA and regional airlines. 2008.

17. Goethe J. Mephistopheles being the devil. 1808.

18. John. Ca. 80 A.D. 2:13-16.

19. Dostoyevsky F. Notes From the Under-ground. 1864.

20. Festinger L. A Theory of Cognitive Dissonance. Stanford University Press; 1957.

21. Festinger L (1957) A theory of social comparison processes. Human Relations. 7(2): 117-140. 